\title{
A realização de atividades acadêmicas no ensino superior em tempos de pandemia: até que ponto é possível?
}

\author{
Performing academic activities in higher education in pandemic times: to \\ what possible is it possible?
}

\author{
iD Givanildo da Silva \\ Doutor em Educação \\ Universidade Federal de Alagoas - UFAL. \\ Maceió, Alagoas - Brasil. \\ givanildopedufal@gmail.com \\ José Diogenes dos Santos Filho \\ Graduando em Pedagogia \\ Universidade Federal de Alagoas - UFAL. \\ Maceió, Alagoas - Brasil. \\ josediogenes15@gmail.com \\ iD Matheus Vieira da Silva \\ Graduando em Pedagogia \\ Universidade Federal de Alagoas - UFAL. \\ Maceió, Alagoas - Brasil. \\ mathsmathus@gmail.com
}

Resumo: A presente pesquisa teve como objetivo perceber a situação dos estudantes do curso de Pedagogia, da Universidade Federal de Alagoas, campus A. C. Simões, em relação às possibilidades de desenvolvimento das atividades acadêmicas. A metodologia da pesquisa esteve pautada em uma perspectiva qualitativa, tendo como técnica o estudo de caso e o questionário como coleta de dados. A partir dos resultados, foi possível analisar a complexidade para a realização de atividades acadêmicas pelos participantes, visto que muitos estão inseridos em uma realidade cuja pobreza estrutural, a exclusão social e a desigualdade econômica são intensas, tendo que enfrentar múltiplos desafios, o que os impede de desenvolver as atividades acadêmicas em tempos de pandemia e de isolamento social.

Palavras chave: pandemia; atividades acadêmicas; ensino superior.

Abstract: This research aimed to understand the situation of students in the Pedagogy course, at the Federal University of Alagoas, campus A. C. Simões, in relation to the possibilities of developing academic activities. The research methodology was based on a qualitative perspective, using the case study and the questionnaire as data collection techniques. From the results, it was possible to analyze the complexity for the performance of academic activities by the participants, since many are inserted in a reality whose structural poverty, social exclusion and economic inequality are intense, having to face multiple challenges, which prevents the development of academic activities in times of pandemic and social isolation.

Key-words: pandemic; academic activities; university education.

Cite como

(ABNT NBR 6023:2018)

SILVA, Givanildo da; SANTOS FILHO; José Diogenes dos; SILVA, Matheus Vieira da. A realização de atividades acadêmicas no ensino superior em tempos de pandemia: até que ponto é possível? Dialogia, São Paulo, n. 38, p. 1-18, e19384, maio/ago. 2021. Disponível em: https:// doi.org/10.5585/38.2021.19384.

American Psychological Association (APA)

Silva, G. da., Santos Filho, J. D. Dos., \& Silva, M. V. da. (2021, maio/ago.). A realização de atividades acadêmicas no ensino superior em tempos de pandemia: até que ponto é possível?. Dialogia, São Paulo, 38, p. 1-18, e19384. https://doi.org/10.5585/38.2021.19384. 


\section{Introdução}

O surgimento da pandemia do coronavírus mostrou os resultados da globalização na sociedade, principalmente pela rapidez na contaminação e propagação do vírus, que a princípio concentrou-se no continente asiático e, rapidamente, disseminou-se pelo mundo. De acordo com Ferreira, Costa e Souza (2020), em um breve percurso, o vírus propagou-se para diferentes continentes, promovendo uma alta escalada de mortes entre as pessoas. No Brasil, mais de 550 (quinhentas e cinquenta) mil vítimas.

Assim, a Covid-19 chegou aos estados brasileiros, de forma que o processo de contágio transpareceu a desigualdade social do país, chegando primeiro à elite econômica por meio das viagens ao exterior e, depois, à classe trabalhadora. Mediante essa questão, por possuir um considerável número de pessoas desfavorecidas que não têm acesso a serviços de saúde de qualidade, água encanada, saneamento básico e condições dignas de moradia, no Brasil, os desafios da Covid-19 são maiores que em alguns lugares do mundo (BARRETO et al. 2020).

É importante destacar que antes da pandemia já havia um histórico de desigualdade e pobreza no Brasil e, agora, principalmente para os pobres e os desempregados, a pandemia é mais um problema, entre tantos outros já existentes. Assim, a falta de investimento na saúde pública evidencia e subtende a ausência de políticas públicas e investimentos em outras áreas da sociedade, sobretudo aquelas que auxiliam a sociedade mais carente, como salientam Barreto et al. (2020, p. 1), "a pandemia por Covid-19 representa um dos maiores desafios sanitários em escala mundial desse século”, uma vez que “a humanidade está diante da maior catástrofe desde a Segunda Guerra Mundial" (COLEMARX, 2020, p. 7).

A Covid-19, inicialmente, forçou as pessoas a isolarem-se, de modo que mudou a rotina de trabalho e de seus afazeres. Assim, as mudanças de comportamento, de hábitos, de organização da vida e de trabalho, os modos de desenvolvimento das aulas foram elementos que estão em pauta nos últimos meses. Uma questão que merece destaque são as evidências das desigualdades sociais que "se mostram explícitas entre os que podem ficar em casa dos que não podem; os que correm mais riscos de exposição ao vírus dos que podem cumprir a quarentena isolados; os que estão mais próximos da infecção dos que se mantêm afastados do vírus" (FERREIRA; COSTA; SOUZA, 2020, p. 176).

As implicações da pandemia para a sociedade são diversas, como "o medo, a ansiedade, a cautela, a preocupação, a solidariedade. O mesmo vale para a mudança generalizada de hábitos como uso constante do álcool em gel e lavagem de mãos, uso de máscaras de proteção e outras medidas de segurança com a higiene" (FERREIRA; COSTA; SOUZA, 2020, p. 168). A propagação 
em massa do vírus também mostrou a falta de investimento governamental na área da saúde pela ausência de respiradores, Equipamentos de Proteção Individual (EPIs) médicos e cirúrgicos e leitos, como também estruturações médicas deterioradas e sem capacidade de receber um considerável número de pacientes.

Outro problema proveniente da pandemia foi o aumento do desemprego, principalmente para os indivíduos de classe média e baixa. Segundo Ferreira, Costa e Souza (2020, p. 174-175), “em tempos de pandemia, a situação social e financeira, no âmbito das relações de trabalho e renda agrava-se mais, quando constatamos que parte significativa dos trabalhadores não consegue exercer as suas atividades em casa (bome office)".

No contexto da educação, a desigualdade social é tida como dimensão primária para atender as necessidades dos estudantes, levando a reflexão das reais possibilidades de efetivar um espaço educacional, mesmo virtual, que contemple as individualidades e a falta de recursos humanos e materiais para efetivar as propostas educativas. Assim, o objetivo da pesquisa foi perceber a situação dos estudantes do curso de Pedagogia, da Universidade Federal de Alagoas (UFAL), campus A. C. Simões, em relação às possibilidades de desenvolvimento das atividades acadêmicas.

A metodologia da pesquisa esteve pautada em uma perspectiva qualitativa, tendo como técnica o estudo de caso (YIN, 2010). O instrumento de coleta de dados foi o questionário, o qual foi divulgado nas redes sociais do Centro Acadêmico de Pedagogia (CAPED), grupos de WhatsApp das turmas do $1^{\circ}$ ao $9^{\circ}$ período de Pedagogia do Centro de Educação e e-mails das turmas, durante o período de cinco a 19 de junho de 2020. Ao todo, 131 estudantes responderam ao questionário. A técnica de análise dos dados foi a exploratória, a qual visa compreender as principais dimensões apresentadas pelos participantes, a fim de alcançar os objetivos propostos.

O texto está dividido em duas partes que se completam, além da introdução e das considerações finais. Na primeira parte, tratam-se das mudanças no cenário da educação, com ênfase para as reflexões acerca das possibilidades de acesso às estruturas humanas e materiais dos envolvidos no processo. E, na segunda, apresentam-se as vozes dos participantes da pesquisa, destacando-se as suas condições de desenvolvimento das atividades acadêmicas.

\section{As mudanças na educação no contexto da pandemia}

A prática de vivenciar os processos educativos é tida como uma dimensão complexa que requer conhecimento do contexto social e político que está sendo vivenciado pelo público para o qual se direciona a mediação pedagógica. O ponto de partida para a construção de possibilidades de aprendizagens é considerar as efetivas condições dos estudantes para operacionalizar a 
construção dos múltiplos conhecimentos, isso porque, sem essa prévia avaliação diagnóstica, não há condições de edificar um caminho formativo que contribua para a formação integral dos estudantes.

O contexto da pandemia para a educação apresentou situações que vão além das condições técnicas e didáticas dos profissionais da área, elas requerem dimensões que estão atreladas às diferentes realidades, especialmente por conta das desigualdades estruturais que assolam o país. Desse modo, as mudanças ocorridas na forma de planejar, de avaliar, de despertar o interesse para aprender são diferentes, esbarrando em um complexo contexto político, social, cultural, econômico e educacional.

O conjunto de rupturas que a pandemia instaurou na educação é uma dimensão expressiva, direcionando novas alternativas para o campo educacional e reconfigurando os papeis dos diferentes envolvidos no processo de ensino, de aprendizagem e de organização das políticas educacionais. Nesse cenário, as percepções sobre o papel da educação reconfiguraram-se em todas as etapas e modalidades da educação, como é possível observar nas indicações do Conselho Nacional de Educação (CNE), de acordo com o parecer, aprovado em 28 de abril de 2020, em que apresenta as diretrizes para a reorganização do Calendário Escolar e a possibilidade de cômputo de atividades não presenciais para fins de cumprimento da carga horária mínima anual, em razão da pandemia da Covid-19.

No referido parecer, percebe-se que as indicações para a realização de possíveis atividades da educação infantil ao ensino superior têm como dimensão basilar as interações por meio das redes de comunicação e das Tecnologias da Informação e Comunicação (TIC), direcionando ações a serem vivenciadas entre os diferentes sujeitos, destacando-se as crianças, os adolescentes, os jovens, os adultos, os idosos e os profissionais da educação.

Nessa dimensão, as mudanças oriundas das novas condições sanitárias no mundo apresentaram um caráter multidimensional no sentido de construir canais educativos, juntamente com empresas especializadas em comunicação, tendo o suporte das tecnologias, favorecendo o processo de comunicação entre comunidade escolar/acadêmica e os estudantes e seus familiares. As aulas remotas estão sendo o epicentro das ações educativas, contribuindo para a continuidade do ano letivo, em determinados sistemas e redes da educação básica, e também no ensino superior, desconsiderando, em algumas realidades, as condições de acesso dos estudantes e dos professores.

$\mathrm{Na}$ visão do Coletivo de Estudos em Marxismo e Educação (COLEMARX), da Universidade Federal do Rio de Janeiro (UFRJ), o acesso à internet é um direito primordial em situações adversas como a atual, especialmente para os estudantes mais vulneráveis, garantindo- 
lhes o direito à aprendizagem e o acompanhamento das atividades educacionais. Para os pesquisadores, o acesso à internet, no século XXI, é um bem necessário, igualmente o acesso a outros direitos sociais como a alimentação, a saúde, a assistência social. Nessa perspectiva, "os meios tecnológicos para interação criativa na internet devem ser popularizados e assegurados para todos os estudantes, especialmente computadores portáteis de qualidade" (COLEMARX, 2020, p. 8).

A discussão que se faz no cenário da educação em tempos de pandemia está atrelada, quase que exclusivamente, às condições de acesso de todos os estudantes por meio de uma significativa rede de acesso à internet, bem como à garantia de ter um computador ou smartphone que possa dar suporte ao uso adequado das atividades previstas. Na visão de Silva, Silva e Gomes (2021, p. 5), "com as novas possibilidades de interação, via plataformas digitais, o processo de mediação pedagógica ficou centrado nas redes (internet), desconsiderando a desigualdade política e econômica que os municípios e os estados brasileiros estão inseridos”. Nesse cenário, é possível perceber diferentes situações que levam à reflexão sobre as verdadeiras condições das aulas remotas/virtuais em tempos de pandemia, considerando a realidade da maioria dos estudantes.

Grande parte dos estudantes não tem acesso à internet por problemas estruturais e pelas condições de desigualdade social em que vivem, sendo necessário que sejam efetivadas políticas públicas com a finalidade de possibilitar o acesso para que possam dar continuidade aos seus estudos, garantindo-lhes os direitos constitucionais previstos na Carta Magna de 1988.

Considerando os diferentes atores que estão envolvidos no processo educacional, cabe levantar uma discussão acerca dos profissionais da educação que estão em uma situação complexa, com intensa carga de trabalho com planejamento, por meio das gravações das aulas, atendimentos virtuais, diferentes instrumentos avaliativos, condições precárias de acesso à internet e muitas cobranças da sociedade, uma vez que o discurso hegemônico tenta "normalizar" o retorno das atividades sociais e econômicas, incluindo as aulas presenciais.

Para o Colemarx (2020, p. 18), o processo de precarização docente não é uma ação recente que surgiu junto com a pandemia, mas "antes mesmo do isolamento social já estava em curso a precarização do trabalho dos professores, seja por conta da terceirização, seja pela expansão do mercado educacional que a tecnologização do setor favorece".

Em um cenário mais amplo, as condições de trabalho dos profissionais da educação, no contexto da pandemia, intensificaram-se e estão fazendo com que aumente a sobrecarga de trabalho, sem levar em consideração as condições de gênero, de responsabilidade social e familiar, bem como a estrutura de saúde em seu sentido pleno. A reflexão que reverbera essas análises pauta- 
se na desvalorização da vida, no pleno estado de saúde mental para um atendimento significativo aos estudantes.

Nessa perspectiva, os estudos do Colemarx (2020, p. 20) colaboram na interpretação de que não há uma preocupação com o contexto social no qual os profissionais da educação estão inseridos, mas o que está em pauta são as possibilidades de continuidade às aulas, aos conteúdos, ao enfretamento da pandemia com o discurso de normalidade. Desse modo, "os empregadores exigem que os professores usem materiais próprios, adquiridos com seus recursos privados, e, também, tenham familiaridade com meios tecnológicos aplicados na educação”.

É importante levantar a defesa de que a mediação pedagógica é uma dimensão da Didática que favorece o processo de ensino e de aprendizagem, mas necessita estar sendo vivenciada em um cenário de formação de envolvimento múltiplo entre professores e estudantes. No entanto, diante das limitações atuais dos estudantes e professores, devido aos fatores já expostos, a mediação pedagógica está comprometida, uma vez que não há uma efetiva troca de saberes, bem como não há um significativo desenvolvimento de aulas pensadas para um determinado público, mas pautada em um padrão uniformizado por meio das plataformas digitais.

No ensino superior, mesmo com estudantes adultos, a estratégia para direcionar as práticas educativas também se insere em um complexo cenário, uma vez que "além das dificuldades de acesso ou não às tecnologias virtuais, se faz necessário compreender a dimensão social da pandemia e a forma como a situação escancara a extrema desigualdade do país e a vulnerabilidade da população mais pobre" (BORBA, et al., 2020, p. 14). Os estudantes do ensino superior, principalmente os das universidades públicas, estão envolvidos em um paradoxo que prejudica a continuidade das atividades acadêmicas.

Os estudantes do ensino superior, mesmo tendo autonomia no processo de construção de conhecimentos, necessitam ter as condições básicas para estarem envolvidos nas aulas remotas, redirecionando os apelos para a garantia do direito à educação, mesmo em tempos difíceis. O discurso que prevalece nos órgãos governamentais é o retorno das atividades, apesar de limitadas, pois "impera-se uma necessidade de buscar-se novas maneiras de fazer as coisas e a palavra de ordem no momento é 'adaptabilidade', tão importante e necessária e há muito praticada" (ANTUNES NETO, 2020, p. 32).

$\mathrm{O} \mathrm{CNE}$, por meio de suas diretrizes, lançou luz às instituições de ensino superior com a finalidade de orientar os possíveis caminhos que poderiam ser trilhados para que as aulas remotas pudessem acontecer. O parecer, número 5 de 2020, apresenta as seguintes alternativas de trabalho para o ensino superior: 
Adotar a substituição de disciplinas presenciais por aulas não presenciais; adotar a substituição de atividades presenciais relacionadas à avaliação, processo seletivo, TCC e aulas de laboratório, por atividades não presenciais, considerando o modelo de mediação de tecnologias digitais de informação e comunicação adequado à infraestrutura e interação necessárias; regulamentar as atividades complementares, de extensão e o TCC; organizar o funcionamento de seus laboratórios e atividades preponderantemente práticas em conformidade com a realidade local; adotar atividades não presenciais de práticas e estágios, especialmente aos cursos de licenciatura e formação de professores, extensíveis aos cursos de ciências sociais aplicadas e, onde couber, de outras áreas, informando e enviando à SERES ou ao órgão de regulação do sistema de ensino ao qual a IES está vinculada, os cursos, disciplinas, etapas, metodologias adotadas, recursos de infraestrutura tecnológica disponíveis às interações práticas ou laboratoriais a distância; adotar a oferta na modalidade a distância ou não presencial às disciplinas teóricocognitivas dos cursos da área de saúde, independente do período em que são ofertadas; supervisionar estágios e práticas profissionais na exata medida das possibilidades de ferramentas disponíveis; definir a realização das avaliações de forma remota; adotar regime domiciliar para alunos que testarem positivo ou que sejam do grupo de risco; organizar processo de capacitação de docentes para o aprendizado a distância ou não presencial; implementar teletrabalho para professores e colaboradores; proceder o atendimento ao público dentro das normas de segurança editadas pelas autoridades públicas e com espeque em referências internacionais; divulgar a estrutura de seus processos seletivos de forma remota totalmente digital; reorganização dos ambientes virtuais de aprendizagem e outras tecnologias disponíveis nas IES para atendimento do disposto nos currículos de cada curso; realização de atividades on-line síncronas de acordo com a disponibilidade tecnológica; oferta de atividades on-line assíncronas de acordo com a disponibilidade tecnológica; realização de testes on-line ou por meio de material impresso entregues ao final do período de suspensão das aulas; e utilização de mídias sociais de longo alcance (WhatsApp, Facebook, Instagram etc.) para estimular e orientar os estudos e projetos (CNE, 2020, p. 18-19).

Percebe-se um conjunto de orientações que o CNE apresenta para que as instituições de ensino superior possam estar regulamentando as aulas remotas, no intuito de caracterizar o retorno das atividades de modo natural, mesmo em um complexo contexto no qual estão inseridos os estudantes. Os desafios que o retorno às aulas evidenciam estão configurados em uma arena de tensões, de limitações e de conflitos que independem de orientações sobre como proceder por meio de técnicas, isso porque os pesquisadores das instituições de ensino superior já o fazem e muito bem feito.

Nessa perspectiva, as mudanças que a pandemia trouxe à tona requerem políticas efetivas que caracterizem a educação pública como espaço de investimentos políticos, sociais, culturais e econômicos, evidenciando a valorização da vida, das particularidades de cada ator social e das possibilidades de construção coletiva de um ambiente que colabore para as possíveis discussões de retorno às aulas.

A escuta sensível aos estudantes e aos diferentes profissionais que compõem o ensino superior faz-se necessária com a finalidade de compreender as reais motivações para o retorno das aulas, bem como o entendimento da realidade dos estudantes, suas reais condições de saúde, de moradia, de alimentação, de sobrevivência, de vida... Enfim, a escuta aos estudantes é o que pode 
redimensionar possíveis ações para pensar o retorno das atividades acadêmicas, concretizando os anseios dos governantes e de parte da sociedade.

Com o objetivo de alcançar os princípios estabelecidos na defesa elencada, a próxima seção apresenta as vozes dos estudantes do curso de Pedagogia da UFAL, com ênfase nas suas percepções sobre as possibilidades de desenvolver atividades acadêmicas em tempos de pandemia.

\section{O contexto da pandemia no ensino superior: as vozes dos estudantes}

A coleta de dados da pesquisa foi realizada em um período de 15 dias com os estudantes do curso de Pedagogia, do Centro de Educação, da UFAL, campus A. C. Simões. O curso funciona nos três turnos (manhã, tarde e noite). Ao todo, 131 estudantes responderam ao questionário e suas principais evidências são refletidas na presente seção.

Dos participantes, $46,1 \%$ estão matriculados do $5^{\circ}$ ao $9^{\circ}$ período e $53,9 \%$ são dos períodos antecedentes ao quinto. Desses estudantes, a maioria $(49,2 \%)$ estuda no matutino, os demais estão matriculados nos turnos noturno $(23,1 \%)$ e vespertino $(20,8 \%)$. Destaca-se, ainda, que $6,9 \%$ dos entrevistados frequentam mais de um turno.

Em relação à faixa etária dos participantes, a maioria tem entre 17 e 20 anos $(33,1 \%)$ e entre 21 a $25 \operatorname{anos}(33,1 \%$ ), os demais têm acima de 26 anos. 90,8\% são autodeclaradas mulheres e 9,2\% autodeclarados homens. Acerca do local onde residem, 64,6\% são da capital e 35,4\% do interior. Desses estudantes, 42,3\% alegaram que, em suas casas, moram com até três pessoas e $57,7 \%$ com até, ou mais, de cinco familiares.

Quando questionados sobre a suspensão das atividades acadêmicas presenciais, 88,5\% pensam que essa ação foi necessária para conter a disseminação do vírus, além de preservar vidas. Percebe-se que grande parte dos estudantes tem uma compreensão de que a suspensão das atividades presenciais foi um aspecto necessário, do ponto de vista de que a vida dos estudantes, dos profissionais da educação e dos seus familiares é mais importante do que o cumprimento do calendário acadêmico.

A respeito da possibilidade de desenvolvimento de atividades acadêmicas em suas residências, 68,5\% disseram que estão conseguindo produzir, mesmo com limitações diversas, enquanto $32,5 \%$ não estão. Ao serem questionados sobre as possíveis atividades acadêmicas que estavam realizando, os estudantes puderam marcar mais de uma opção, destacaram-se: 76\% (95) leituras diversas; 19,2 (24) artigos e monografias; 47,2\% (59) participaram de eventos on-line; 19,2 (24) tiveram encontros e reuniões virtuais com colegas e professores; 55,2\% (69) fizeram cursos on-line e, 10,4 (13) realizaram estudos para o desenvolvimento de projetos de pesquisa, destacando- 
se o Programa Institucional de Bolsas de Iniciação Científica (PIBIC), de extensão e do Programa Institucional de Bolsa de Iniciação à Docência (PIBID).

O histórico político e social brasileiro é protagonizado, em muitas realidades, pelas injustiças sociais, exclusões e desigualdades econômicas. De acordo com os depoimentos, muitos estudantes alegaram que são impedidos de realizarem atividades acadêmicas pela falta de condições financeiras e de acesso a um lugar adequado de estudos, uma rede de internet de qualidade e materiais para a execução das tarefas como computadores, tablets e notebooks.

Tenho dificuldade em estudar em casa, pois não tenho espaço individual e não tenho acesso ao computador.

Não tenho notebook/computador para que eu consiga realizar atividades de estudos.

Não possuo conexão boa com a internet nem um computador ou notebook.

Falta de espaço adequado, internet de baixa qualidade e cansaço mental e emocional.

Perdi minha vaga do estágio, então estou fazendo trabalhos manuais e máscaras para ganhar uma renda extra, além disso tenho apenas 1 computador, e meu marido está tendo aulas on-line e o usa com frequência, então não tenho como utilizá-lo.

Não possuo computador para desenvolver determinadas atividades que a plataforma não abre em celular com boa qualidade.

Há a problemática de possuir apenas um notebook, pois preciso dividir com meu irmão que está tendo atividades e aula on-line referente à escola e estudando para o Enem, sendo necessário dividir e organizar o tempo de uso.

Tenho que dividir o espaço de estudo com minha irmã (que tem aula on-line diariamente em tempo integral). Além dos barulhos aos arredores.

Além daqueles que não possuem um material didático, ficou perceptível, nas respostas, que alguns que possuíam algum meio de realizar as atividades ficavam impossibilitados de produzir, por conviver com mais de uma pessoa na residência e não terem condições suficientes para suprir a necessidade de todos, por isso "o uso dos artefatos tecnológicos, por suposto, não pode ser pensado de modo desvinculado das condições de habitação dos estudantes da educação básica e superior" (COLEMARX, 2020, p.16). Dessa maneira, salienta-se que é necessário ter um espaço adequado e materiais disponíveis para os estudantes realizarem suas atividades acadêmicas.

Outros apresentaram a necessidade de optar entre a sobrevivência ou os estudos, visto que, por estarem em uma situação econômica delicada e sem o apoio de algum auxílio governamental, tiveram que abdicar das produções acadêmicas para realizarem atividades comerciais em prol do sustento da família. Essa realidade foi comentada por alguns participantes da pesquisa quando sinalizaram: "tive que priorizar a sobrevivência, minha bolsa estágio foi cancelada, trabalho 12 horas diárias confeccionando máscaras em casa" e "estou trabalhando com meus pais, no nosso 
restaurante, porque tivemos que suspender o contrato dos funcionários por falta de dinheiro. Nenhum de nós está recebendo auxílio algum".

Diante dos depoimentos, percebe-se que se na realidade de muitos indivíduos já havia desafios econômicos, acadêmicos e sociais antes da pandemia, com a chegada do vírus e das medidas de isolamento social, esses desafios aumentaram (PORTO, 2020), transparecendo a desigualdade social do país.

Outra evidência marcante nos resultados da pesquisa foi a questão do gênero e do papel que cada um (homem/mulher) desempenha nas atividades sociais. O curso de Pedagogia da UFAL é majoritariamente composto por pessoas autodeclaradas mulheres (90,8\%). Muitas delas são donas de casa, mães, do campo, da periferia, trabalhadoras informais e que exercem outras atividades além das práticas acadêmicas. De acordo com Borba et al. (2020, p. 6), "em um contexto histórico estruturado pelo patriarcalismo e machismo, as mulheres ainda são as principais responsáveis e responsabilizadas pelos cuidados com o lar e de familiares (filhos, pais, avós, irmãos etc.), que as expõem em duplas jornadas de atividades". Com o cancelamento das aulas presenciais em creches e escolas, muitas mulheres, além de dedicar seu tempo às demais atividades cotidianas, também se engajaram, ainda mais, nos cuidados dos seus filhos.

Esses aspectos ficaram explícitos nos seguintes depoimentos:

Tenho um filho pequeno que ocupa todo o meu tempo e estou sem condições de comprar um computador para poder estudar.

Minhas atividades domésticas como dona de casa, esposa e mãe de dois filhos! Tenho um filho de 1 ano e 1 mês e minha segunda filha acabou de nascer há 1 mês, então minha rotina tem sido puxada e não tem restado tempo para me dedicar às atividades acadêmicas, infelizmente.

Meus filhos requerem muito de mim o tempo todo e não tenho muito tempo pra me dedicar a atividades acadêmicas... O silêncio só é possível quando as crianças dormem e quando isso acontece eu preciso dormir também.

Dessa maneira, levando em consideração o contexto histórico e social do nosso país e os posicionamentos das estudantes, ficou expresso, na rotina dessas mulheres, o fluxo e sobrecarga de atividades particulares, além dos compromissos universitários, o que implica na produção de atividades acadêmicas. Nessa perspectiva, cabe refletir que é preciso exigir de cada um o que é possível desenvolver, pois enquanto uns têm a oportunidade de produção devido à rotina menos atarefada, outras pessoas, especialmente as mulheres que historicamente enfrentam muitos desafios devido às atividades rotineiras excessivas, ficam impossibilitadas de dedicarem maior tempo às elaborações universitárias. 
Alguns estudantes explicitaram que a sua rotina, no período de isolamento social, está sendo "estressante", "confusa", "chata”, “monótona e repetitiva”, “meio conturbada", "descontrolada", "se tratando do Covid-19", “desorganizada", "bastante desregulada". Os aspectos sinalizados, por parte dos estudantes, evidenciaram as mudanças de organização das atividades, de modo que repercutiram no modo de agir, sentir e viver. Outros estudantes, por terem realidades diferentes, destacaram:

No início, estava realizando a pesquisa e escrita da monografia, assim como participando de eventos voltados para a formação, mas a monografia foi concluída e as particularidades do dia a dia acabam dificultando ou impossibilitando a participação efetiva nas atividades on-line que me propus participar, se dando principalmente por cansaço e desânimo. No início do isolamento, consegui lidar com as demandas que me propus, mas atualmente não estou conseguindo.

Cuidado com a casa e filha! Leitura de jornais e textos pelo celular. Realização de atividades do trabalho. Acompanhamento de seminários e cursos pela internet, bem como está sintonizado em rádios e canais educativos e informativos pela plataforma do YouTube. Também há a reserva de horário para atividades físicas.

Com o isolamento social, temos mais um espaço de "tempo livre" para fazer algumas leituras, particularmente pelo celular e revisão do que já estudei esse tempo na UFAL. Porém, não está sendo fácil, encontro dificuldades, pois só tenho internet pelos dados móveis quando coloco créditos. Com certeza, tendo aulas on-line eu não ia conseguir fazer as atividades com sucesso.

A rotina está completamente diferente, tivemos que nos adequar às novas formas de agir, a novos hábitos e costumes, porém, necessários. Contudo, uniu um pouco mais a família, promoveu um exigente controle psicoemocional para evitar o estresse, aumentou a nossa fé e a esperança por dias melhores, mesmo diante desse terrível contexto de calamidade pública da saúde mundial, o processo educacional não pode parar, assim sendo, estou na expectativa de voltar às aulas.

Surpreendente. A princípio considerei que não realizaria nenhuma atividade, mas ao decorrer do tempo fui me adaptando ao cenário de isolamento e aproveitando o tempo em casa para desenvolver estudos, pesquisas e leituras.

O período de isolamento social está causando diferentes sentimentos nas pessoas, ocasionando situações que interferem no dia a dia e na realização de suas atividades. De acordo com os resultados da pesquisa, ficou evidente que grande parte dos participantes destacou o atraso no calendário acadêmico como a maior consequência do isolamento social. Possivelmente, a preocupação com o atraso, para alguns, na conclusão do curso, pode acarretar na sua inserção no mercado de trabalho, além de diminuir as possibilidades de estar com um diploma à disposição para atuar profissionalmente e realizar concursos públicos.

Além dos aspectos mencionados, pode-se expor alguns destaques nas vozes dos participantes, como: 
Sofro de ansiedade, então o retorno vai ser complicado. Não sabemos sobre os prazos que foram paralisados no início da pandemia, por isso estou preocupada. Mas creio que tudo isso é necessário para preservar vidas. Já enfrentamos tantas greves (de servidores e de estudantes). Vamos nos reestruturar novamente...

É uma grande perda, mas é uma medida necessária. Nem todo estudante tem acesso à internet; eu, por exemplo, me esforço dentro das possibilidades que tenho. Estudar é transformação em todos os aspectos de vida. É também melhorar algumas situações vívidas. É uma luta entre a vida, a prevenção e a possibilidade de voltarmos às aulas. A UFAL para mim é muito importante fazia muitas atividades acadêmicas.

Uma situação muito delicada, na qual faz com que tenhamos uma grande perda no ritmo de estudos. Porém, os mais prejudicados (ao meu ver), são os alunos com deficiências. Já que muitos não têm auxílio de outras pessoas.

As consequências são horríveis, pois muitos alunos, assim como eu já vinha animada com o curso, com as diversas matérias, a pressão dos estágios e quando tudo isso para de repente. Se cria um vazio dentro de nós, estudantes, pois não sabemos como reagir diante de tudo isso que está acontecendo e como consequência entramos em uma espécie de desaceleração. Nossa rotina fica abalada e não conseguimos fazer quase nada de proveitoso.

Creio que há apenas uma consequência: a demora na formação acadêmica. Fora isso, se a faculdade optar por não ter EAD, o estudante preservará sua saúde mental para conseguir passar essa fase de isolamento necessário e voltará às aulas normalmente, sem nenhum trauma psicológico ou cansaço.

Os apontamentos sinalizados nos depoimentos dos participantes mostram que além da preocupação com o atraso na conclusão de curso e no andamento das atividades acadêmicas formalmente, há situações que evidenciam a preocupação com o atendimento a todos com o efetivo acesso à internet e com condições de desenvolvimento das atividades, a saúde mental dos estudantes e demais profissionais, uma vez que o trabalho remoto e as aulas on-line podem trazer consequências psicológicas e educacionais para todo o público envolvido.

Nessa perspectiva, "defende-se que, no século XXI, o acesso à internet é um direito fundamental, a exemplo dos direitos, ainda não assegurados" (COLEMARX, 2020, p. 8). A concretização de políticas públicas que consolidem o direito à internet para a realização das atividades acadêmicas faz-se necessária com a finalidade de alcançar os direitos constitucionais, principalmente em realidades regionais que exprimem a desigualdade social em muitos aspectos, como a educação, a saúde, o transporte, a moradia, entre outros.

Desse modo, salienta-se que há diferentes realidades no espaço acadêmico e eles devem ser apreciados com zelo pela comunidade universitária, com o propósito de atender as reais necessidades dos estudantes e demais profissionais. Mesmo com sentimento de falta do convívio universitário, os depoimentos dos participantes mostram a compreensão da necessidade do isolamento social e da relevância da gestão da universidade perceber os limites que as aulas remotas possibilitam para os estudantes. 
Uma dimensão importante, no contexto da pandemia, é as possibilidades que a internet oferece para aqueles que têm condições de acesso. Com o isolamento social, muitos grupos de pesquisas e diferentes projetos das universidades brasileiras iniciaram um processo de comunicação com a sociedade, estreitando as relações, por meio de transmissões de eventos, lives, seminários e diferentes formatos que apresentam ao público a possibilidade de participação. Essa ação foi destacada por um participante da pesquisa:

Em relação a mim, em específico, ainda não tive nenhum contato com professores ou
atividades específicas do curso durante o isolamento, mas tenho buscado
conhecimento por meio de outros canais. Nas redes sociais, nas quais estou presente,
os estudantes trocam informações de seminários e eventos on-lines sobre a área e isso
tem ajudado a acompanhar o debate dos impactos que a pandemia tem trazido para
educação de forma geral e para a Pedagogia.

Nesse cenário, observa-se que, mesmo não tendo contanto direto com a universidade da qual faz parte, os estudantes têm, de alguma forma, possibilidades de vivenciar atividades acadêmicas que lhes interligam com os saberes do universo educacional e universitário, favorecendo conhecimentos e interação com a realidade atual. Esse fenômeno é vivenciado por meio da difusão das TIC e da internet, as quais estão presentes no cotidiano da sociedade em geral. No entanto, é válido ponderar que as estruturas sociais e as desigualdades que se fazem presentes nas diferentes regiões do país consolidam a alienação a um bem necessário no contexto da pandemia.

Os diálogos acerca das desigualdades estruturais no Brasil levam à reflexão de que "num contexto de grande desigualdade social e demográfica, com populações vivendo em condições precárias de habitação e saneamento, sem acesso constante à água, em situação de aglomeração e com alta prevalência de doenças crônicas" (BARRETO et al., 2020, p. 2), fica evidente que muitos direitos sociais não chegam a toda população, deixando a parte um contingente significativo de brasileiros, incluindo, nesse contexto, o direito à educação pública de boa qualidade.

Para Borba et al. (2020), é necessário considerar as diversas vulnerabilidades socias que se sobrepõem às questões tecnológicas, isso porque há diferentes dimensões que impactam na realização das atividades acadêmicas pelos estudantes. Assim, "para além da capacidade e velocidade da internet, deve-se considerar o tipo de tecnologias (computador, celular, tablet), o seu tempo de uso, a compreensão e manuseio dos seus componentes e interfaces, os componentes e habilidades necessárias para o desempenho” (p. 12) no uso das atividades virtuais. Outra questão que merece atenção é a acessibilidade dos "estudantes com deficiência, e o ambiente, que se espera adequado, com certo isolamento e silêncio que permita a concentração. Ainda, há que se considerar 
a situação familiar, a renda para as necessidades mais básicas, jornadas de trabalho e/ou de cuidado com o lar, entre outros" (BORBA, et al., 2020, p. 12).

Com o processo de desigualdade social, surgem diferentes desafios que os estudantes do ensino superior vivenciam, os quais repercutem no desenvolvimento das atividades em tempos "normais", intensificando ainda mais no período de isolamento social. Os participantes destacaram que:

A maior dificuldade é lidar com a nova rotina com duas crianças pequenas em casa que são totalmente dependentes de mim. A rede de apoio que tenho é o que torna a vida um pouco mais tranquila nesse momento, mas estou aproveitando esse momento de isolamento social para curtir os meus filhos e me dedicar a eles $100 \%$, pois as crianças crescem rápido e momentos assim não voltam mais.

Não poder ter a vida de antes é uma delas, é muito triste não poder sair como antes, visitar a família, ir à Universidade. Sem falar na dificuldade que ficou aqui em casa, meu pai acabou perdendo o emprego e temos que nos virar com o auxílio emergencial, que é um valor bem inferior do que estávamos acostumados antes, é bem difícil ter que escolher o que é necessário e o que não é...

O conhecimento é histórico e social, desta forma, o mesmo deve ser compartilhado e construído coletivamente. Com o isolamento social, as dificuldades são muitas, partindo do pressuposto que o diálogo e a comunicação são essenciais para tal objetivo, mesmo que por meio das redes sociais, o contato, a relação e o diálogo para trocas de ideias são extremamente importantes. Com isso, a minha maior dificuldade é o presencial, mas também a orientação, ferramentas tecnológicas como um notebook.

Minha saúde mental está bastante abalada. Às vezes me sinto triste, às vezes estou muito bem, e é isso que mais dificulta as coisas porque me sinto improdutivo por estar triste ou desanimado e não conseguir fazer nada.

O impacto na questão financeira é a maior dificuldade para mim, fora a preocupação com pessoas conhecidas que estão enfrentando a doença. Esse momento gera ansiedade e medo e muitas vezes isso prejudica até a concentração para estudar e produzir.

As consequências do isolamento social e da paralisação presencial das atividades acadêmicas trouxeram impactos na vida e na rotina dos estudantes, os quais, além de estarem isolados, estão vivenciando questões que os desafiam, principalmente porque envolvem outras dimensões, como a familiar. As respostas dos participantes estiveram centradas em aspectos muito semelhantes, as quais evidenciaram as preocupações com a saúde mental, a questão financeira e a dificuldade de organização para consolidar um espaço de estudo, visto que são muitos os desafios enfrentados.

No que se refere à saúde mental, destacaram-se nos relatos dos estudantes aspectos como "ansiedade", "estar sozinha”, "medo de me contaminar com esse vírus", “ansiedade, nervosismo, crises de choro”, “depressão”, “sobrecarga de trabalho”, “incerteza”, "falta de rotina, insônia e má alimentação", "solidão", "rotina do sono", "estou em luto, com medo e 
trabalhando muito para sobreviver", "distanciamento familiar", "medo ocasionado pelo cenário atual”, "cansaço, insônia ou sono desregulado, estresse, ansiedade e desânimo”.

O equilíbrio de manter a saúde mental estável é um desafio para toda a população. Além das ameaças que surgem, oriundas da Covid-19, há os apelos humanos de sobrevivência, os quais requerem uma atitude de ir à procura de resoluções de conflitos e das necessidades imediatas. Os problemas repercutem diretamente no modo de viver das pessoas, causando-lhes medo, ansiedade, insônia e outras questões destacadas pelos estudantes.

$\mathrm{Na}$ visão de Borba et al. (2020), com o processo de reorganização das forças políticas, há um forte desmonte das políticas públicas, o qual reverbera diretamente na vida dos estudantes do ensino superior e em suas famílias. Assim, "compreender a dimensão social da pandemia e a forma como a situação escancara a extrema desigualdade do país e a vulnerabilidade da população mais pobre é mais do que necessário" (2020, p. 15). Cabe, ainda, a elaboração e a intensificação de estratégias que possam contribuir com a garantia do direito à educação aos estudantes, de modo que as políticas públicas possam efetivar o direito garantindo nos dispositivos legais na oferta de uma educação pública para todos, como preconizam a Constituição Federal de 1988 e a Lei de Diretrizes e Bases da Educação Nacional, 9.394, de 20 de dezembro de 1996.

\section{Considerações finais}

A pandemia da Covid-19 é uma gravidade que se faz presente em todas as dimensões sociais, repercutindo no modo de organização e vivência das pessoas, além de interferir nas atividades desenvolvidas pela maioria da população brasileira. No cenário da educação superior, essa complexidade intensifica-se por diferentes motivos, tendo como dimensão basilar a desigualdade social presente nas regiões do país.

No contexto da realidade do curso de Pedagogia, do Centro de Educação, da UFAL, campus A. C. Simões, o equilíbrio da saúde mental também tem sido um desafio para a maioria dos estudantes, intervindo nos motivos que impedem a realização das atividades acadêmicas. Os indivíduos, já fragilizados por outros desafios sociais e econômicos, deparam-se com mais um complexo problema que interfere em todas as dimensões sociais, o isolamento social. Os acontecimentos ocasionados pela Covid-19 refletem uma colcha de retalhos de comportamentos, de sensações e de posturas, destacando-se o medo, a ansiedade, a cautela, a preocupação, a solidariedade (FERREIRA; COSTA; SOUZA, 2020). Expressões como depressão, ansiedade, indisposição, pressão psicológica e exaustão foram frequentes nos comentários dos graduandos que participaram da pesquisa. 
Analisando os posicionamentos de grande parte dos participantes da pesquisa, observa-se que, além de desafios de cunho social e econômico que estão ligados às realidades dos estudantes, como a pobreza, o desemprego e a sobrecarga de atividades, a pandemia ocasionou ou intensificou em muitos deles problemas emocionais, impedindo o vigor do bem estar físico e psicológico e, consequentemente, a disponibilidade para as produções acadêmicas.

Diante dos resultados, foi possível analisar, no cenário atual do país, a complexidade da realização de atividades acadêmicas pelos participantes, visto que muitos estão inseridos em uma realidade cuja pobreza estrutural, a exclusão social e a desigualdade econômica são intensas, tendo que enfrentar múltiplos desafios, o que lhes impede de realizar e produzir atividades acadêmicas em tempos de pandemia e isolamento social.

Por se tratar de uma complexidade que vai além das questões sanitárias, é necessário que as múltiplas possibilidades de amenização das problemáticas dos estudantes no processo de desenvolvimento das atividades acadêmicas sejam dialogadas com toda a comunidade acadêmica e a sociedade direcionando ações e perspectivas que possam enxergar os melhores caminhos para todos, do ponto de vista da realização das atividades acadêmicas obrigatórias.

Além dos cuidados com as situações apresentadas, é preciso ter a sensibilidade e o cuidado com a valorização da vida, como dimensão primária, a fim de intensificar a defesa de que as pessoas são as maiores preocupações do poder executivo e da esfera pública, sinalizando o papel do Estado no complexo cenário que atravessa o Brasil.

O papel do Estado na consolidação de ações que possam contribuir com as problemáticas das pessoas, especialmente as mais vulneráveis, é relevante no favorecimento de políticas sociais que tenham como base o cuidado com a vida, com a saúde mental e com as necessidades básicas do ser humano. Nessa direção, as universidades também têm um importante papel na construção e na colaboração de práticas que intervenham na inclusão dos estudantes que estão à margem e na busca de resolução dos conflitos que estes vivenciam, do ponto de vista do acesso, da permanência e do sucesso das atividades acadêmicas.

Por fim, cabe levantar a defesa da construção de uma sociedade e de um espaço público em tempos de pandemia que lutem pela inclusão de todos, sinalizem a vida como dimensão primária, construam políticas no intuito de favorecer os que mais precisam, tendo o ser humano como fator de preocupação primária e concretizem práticas nas quais todos os excluídos e marginalizados possam estar inseridos nas ações do Estado em detrimento da realização de um calendário acadêmico com a perspectiva de apresentar uma "normalidade" às questões sociais, incluindo, nesse contexto, a educacional. Eis, portanto, o desafio! 


\section{Referências}

ANTUNES NETO, J. M. F. Sobre ensino, aprendizagem e a sociedade da tecnologia: por que se refletir em tempo de pandemia? Revista Prospectus, v. 2, n. 1, p. 28-38, fev.-ago., 2020. Disponível em: < https://prospectus.fatecitapira.edu.br/index.php/pgt/article/view/32>, acesso em $16 \mathrm{de}$ jun. de 2020.

BARRETO, M. L. et al. O que é urgente e necessário para subsidiar as políticas de enfrentamento da pandemia de COVID-19 no Brasil? Revista Brasileira de Epidemiologia, Rio de Janeiro, v. 23, n. 1, p. 1-4, 2020. Disponível em: < https://www.scielo.br/scielo.php?pid=S1415-

790X2020000100101\&script=sci_arttext>, acesso em 15 de jun. de 2020.

BORBA, P. L. O. et al. Desafios 'práticos e reflexivos' para os cursos de graduação em terapia ocupacional em tempos de pandemia. Cadernos Brasileiros de Terapia Ocupacional, São Carlos, v. 28 , n. 2, p. 1-18, junho de 2020. Disponível em:

<https://preprints.scielo.org/index.php/scielo/preprint/view/790>, acesso em 16 jun. 2020.

BRASIL. Conselho Nacional de Educação. Reorganização do Calendário Escolar e da possibilidade de cômputo de atividades não presenciais para fins de cumprimento da carga horária minima anual, em rąãa da Pandemia da COVID-19. Resolução CNE/CP, n 5/20, aprovado em 28 de abril de 2020.

BRASIL. Constituição Federal de 1988. Brasília, 1988.

BRASIL. Lei n. 9.394, de 20 de dezembro de 1996: estabelece as Diretrizes e Bases da Educação Nacional. Brasília, DF: Biblioteca Digital da Câmara dos Deputados, 1996.

BRASIL. Medida Provisória nº 936, de $1^{\circ}$ de abril de 2020. Disponível em: < http://www.planalto.gov.br/ccivil_03/_ato2019-2022/2020/mpv/mpv936.htm>, acesso em 20 de jun. de 2020.

BRASIL. Medida Provisória no 956, de 24 de abril de 2020. Disponível em: < https://www.congressonacional.leg.br/materias/medidas-provisorias/-/mpv/141699>, acesso em 20 de jun. de 2020.

COLEMARX. Em defesa da educação pública comprometida com a igualdade social: porque os trabalhadores não devem aceitar aulas remotas. Universidade Federal do Rio de Janeiro. Rio de Janeiro, 22 de abril de 2020. Disponível em: < http:/ /www.colemarx.com.br/wpcontent/uploads/2020/04/Colemarx-texto-cr\%C3\%ADtico-EaD-2.pdf $>$, acesso em 10 de maio de 2020 .

FERREIRA, L. C.; COSTA, C. F. L.; SOUZA, J. P. S. O enigma da pandemia do Covid-19: solidariedade, formação humana e cidadania em tempos difíceis. Revista Augustus, Rio de Janeiro, v. 25, n. 51, p. 165-182. jul./out. 2020. Disponível em: < https://revistas.unisuam.edu.br/index.php/revistaaugustus/article/view/562>, acesso em 15 de jun. de 2020. 
PORTO, M. F. No meio da crise civilizatória tem uma pandemia: desvelando vulnerabilidades e potencialidades emancipatórias. Revista Visão em Debate, v. 8 , n. 1 , p. 1-9, abr. de 2020.

Disponível em:

$<$ https://visaemdebate.incqs.fiocruz.br/index.php/visaemdebate/article/view/1625>, acesso em 15 de jun. de 2020.

SILVA, G. da.; SILVA, A. V. da.; GOMES, E. P. da S. A gestão escolar em tempos de pandemia na capital alagoana. Jornal de Políticas Educacionais. V. 15, n. 1. Janeiro de 2021. Disponível em: <https://revistas.ufpr.br/jpe/article/view/77531>, acesso em 29 de jul. 2021.

YIN, R. Estudo de Caso: planejamento e métodos. Tradução: Ana Thorell; revisão: Cláudio Damacena. Porto Alegre: Bookman, 2010. 